\title{
Study of microcirculation in oral lichen planus by video-capillaroscopy
}

\author{
Giuseppe Alessandro Scardina, DDS, PhD, ${ }^{\mathrm{a}}$ Vito Picone, DDS, ${ }^{\mathrm{b}}$ Antonio Cacioppo, DDS, ${ }^{\mathrm{c}}$ and \\ Pietro Messina, MD, MS, ${ }^{\mathrm{d}}$ Palermo, Italy \\ UNIVERSITY OF PALERMO
}

\begin{abstract}
Objective. The aim of this study was to evaluate "in vivo" the oral microcirculatory characteristics in patients with oral lichen planus (OLP) and to discover any differences in microcirculation in comparison with healthy patients. Study design. Twenty patients with established diagnosis of OLP and 20 healthy patients were examined in our laboratory by means of contact optical probe videocapillaroscopy. The examined areas for each patient were the right and the left buccal mucosae. Capillary density and total capillary diameter, as well as afferent and efferent loop diameter were studied; the discovery of characteristic (tortuous, branched) loops was also investigated.

Results. The results were observed by 2 different researchers using the capillaroscope's software. Capillary density and the diameter of the afferent and efferent ansa were found to be significantly increased in OLP patients compared with controls. There was also a significant difference between the study of capillary tortuousity and the discovery of characteristic branched loops, indicating angiogenesis.

Conclusions. Our methodology allowed an in vivo observation of the angiogenesis. Angiogenesis was interpreted as an increase in capillary density, total vascular caliber, and afferent and efferent loop caliber; the discovery of tortuous, branched loops, indicating the angiogenic phenomenon in vivo, was particularly significant. The capillaroscopy in correspondence with the lesion can be a very important method in the evaluation of the microcirculation of the patients suffering from OLP. (Oral Surg Oral Med Oral Pathol Oral Radiol Endod 2007;103:e30-e34)
\end{abstract}

Oral lichen planus (OLP) is a chronic inflammatory pathology with immunologic pathogenesis. The percentage of malignant evolution is controversial. From $1 \%$ to $1.5 \%$ of the patients are likely to undergo this evolution after 10 years. ${ }^{1,2}$

Once diagnosed, this pathology is subject to periodic controls and follow-ups. Since the risk of lesion evolution must be always kept in mind, it is fundamental to have techniques at our disposal that, based on objective data, permit a rapid detection of those lesions that show a real risk of evolution, so that an early diagnosis can be made.

Several studies have shown that local microcirculation modifications, particularly referred to as angiogenesis, play a key role in possible lesion evolution. ${ }^{3-10}$ Angiogenesis, the formation of new blood vessels, is a crucial process in a number of physiological processes, such as reproduction, development, and tissue repair, as

Received from the Department of Oral Sciences, University of Palermo, Italy.

${ }^{\mathrm{a} A s s i s t a n t}$ Professor.

${ }^{\mathrm{b}}$ Member, Odontostomatological section.

${ }^{\mathrm{c}}$ Member, Odontostomatological section.

${ }^{\mathrm{d}}$ Professor, Department of Oral Medicine.

Received for publication Feb 15, 2006; returned for revision Oct 4, 2006; accepted for publication Oct 20, 2006.

$1079-2104 / \$$ - see front matter

(c) 2007 Mosby, Inc. All rights reserved.

doi:10.1016/j.tripleo.2006.10.022 well as in disease states including, among others, inflammatory diseases such as OLP. The phlogistic phenomenon is also linked to a greater or lesser damage to the basal epithelium, and therefore to a greater or lesser "activity" of the disease. Capillaroscopy is a method for studying microcirculation that arouses great interest, since it allows the observation in vivo of small vessels using a microscope. ${ }^{11-13}$

The study aimed at evaluating possible differences in the vascular pattern between healthy patients and patients suffering from OLP, and at directing attention on the possible angiogenetic process.

\section{PATIENTS AND METHODS}

Twenty patients with established diagnosis of OLP (11 women and 9 men; mean age $\pm \mathrm{SD}=60.25 \pm$ 12.47 ; range $=33-84)$ and 20 healthy patients (12 women and 8 men; mean age $\pm \mathrm{SD}=59.94 \pm 13.31$; range $=27-79)$, in all 40 patients, were examined in our laboratory by means of contact optical probe videocapillaroscopy.

All the patients gave their informed consent according to Italian law. The patients belonging to the control group did not show any systemic pathology that could alter microcirculation. Besides the patients assuming systemic drugs (antihypertensive, oral hypoglycemizing drugs, anti-inflammatory), those with amalgam fillings and smokers were not included in the 2 groups.

OLP patients showed clinical signs of the pathology 
in correspondence with the right and the left buccal mucosa. The lesions were clinically distinguished as type 1 reticular lichen (5 patients), type 2 atrophic lichen (8 patients), and type 3 erosive lichen ( 7 patients).

Capillaroscopy was randomly carried out in the group before the beginning of every therapeutic protocol. The videocapillaroscopic investigation was carried out with a contact optical probe videocapillaroscopy at $\times 200$ magnification (DS Medigroup, Milan, Italy). The investigation was carried out with the patients in a sitting position, with the same light source, at the same temperature $\left(23^{\circ} \mathrm{C}\right)$, in the morning, by the same operator, and repeated twice for each examined area. The examined areas for each patient were the right and the left buccal mucosa. Two independent observers examined all the images. The intraobserver and interobserver variability was assessed with the 2 observers evaluating twice the same randomly selected images.

The following static parameters were used:

- Nonparametric data: Capillary loop visibility (marks from 1 to 4): (1) simple focusing = within $30 \mathrm{sec}$ onds from the beginning of the examination; (2) average focusing $=$ over 30 seconds and within 2 minutes; (3) difficult focusing = over 2 minutes; (4) impossible focusing. Orientation regarding the surface (marks A, B or AB): (A) capillary loop course parallel to the surface; (B) capillary loop course perpendicular to the surface; $(\mathrm{AB})$ both parallel and perpendicular. Capillary tortuosity (marks from 0 to 3): (0) absence of crossing in the capillary loops; (1) presence of crossing; (2) greater presence of crossing; (3) complete distortion of the capillary loops. Microhemorrhages (marks 0 or 1): (0) absence; (1) presence. Characteristics of the capillary loops (marks 0 or 1): (0) absence; (1) presence.

- Parametric data: number of visible capillary loops per square millimeter (value obtained from the average of the 2wo observations for each examined area); capillary loop caliber (values obtained from the average of the 2 wo observations for each examined area).

As regards the parametric data, it must be stressed that they originate from the software connected to the videocapillaroscope. The system is specifically calibrated: every optical magnification corresponds to an exact metric pixel value in the digitalized image; therefore, the capillary caliber can be measured with a high degree of precision. The statistical significance of the differences between the healthy and the LPO patients was checked with the Student $t$ test for independent samples with regard to parametric data, and with the Mann-Whitney test (MW test) with regard to nonpara- metric data. The level of significance was set to $P<$ .05. Data analysis was carried out with StatView 5.0.1 (SAS Institute Inc, Cary, NC). The results obtained from each examined area represent the average values of the 2 observations.

\section{RESULTS}

Vessel bed visibility was easy to achieve in the areas with lining mucosa because of its thin layer (mark 1). The microcirculation architecture of lining mucosa was referable to type I of Curri classification (polygonalmeshed capillary net with a pattern parallel to the surface), with some aspects more similar to group B (very long capillary loops with even caliber and hairpin shape) than to group A (short, stubby, rather wide loops with a stirrup morphology). ${ }^{11}$ The loops examined in both groups showed an even diameter, but a variable pattern and length; besides those with the typical stirrup shape, there were others with a hairpin, comma, and corkscrew shape, as well as rare microhemorrhages in the form of reddish spots, which could be traced back to possible micro traumas. The definition of normal or pathological condition was dictated by differences in loop diameter or length, by architectural disorder, or by the presence of morphological abnormalities and microhemorrhages. Particularly interesting was the discovery of characteristic (tortuous, branched) loops in the OLP group, with a significant difference compared to the control (Figs. 1-3). The density, length, and caliber parameters of capillary loops showed significant differences between the 2 groups examined (Table I). Some parameters (density) showed very significant differences if the 3 types of OLP are considered (Table II).

\section{DISCUSSION}

To our knowledge, this is the first scientific study in which videocapillaroscopy was used for the morphological evaluation of microcirculation in OLP patients. Oral lichen planus is a lesion considered potentially malignant, with an evolution percentage of approximately $1 \%$ to $1.5 \% .^{2}$ The issue of a malignant potential of OLP has been a matter of serious controversy. Silverman $^{10}$ and Wright ${ }^{14}$ have stated that some of the reported OLP cases developing oral cancer were in fact not OLP, but rather dysplastic lesions with lichenoid features. The aim of a periodic control is to detect those modifications that lead the clinician to assume a progress or evolution of the lesion, and therefore to organize the proper therapeutic program. Another key element of the follow-up is not only to intercept lesion evolution, but also to do this in the early stages. Several studies have shown that angiogenesis is a phenomenon associated with a malignant lesion evolution. 3,5-7,9,15-17 Angiogenesis is linked to a modification in local mi- 


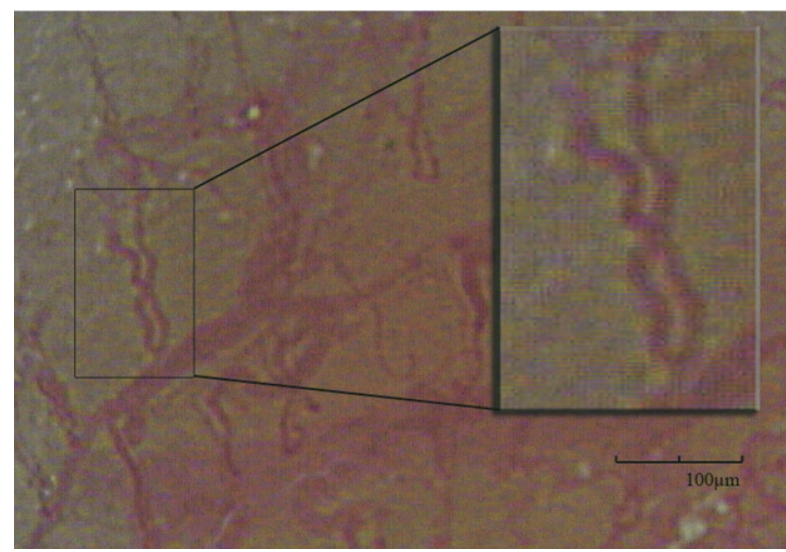

Fig. 1. Microvascular capillaroscopic characteristics of oral lichen planus showing the increase of the capillary calibre; magnification $\times 200$.

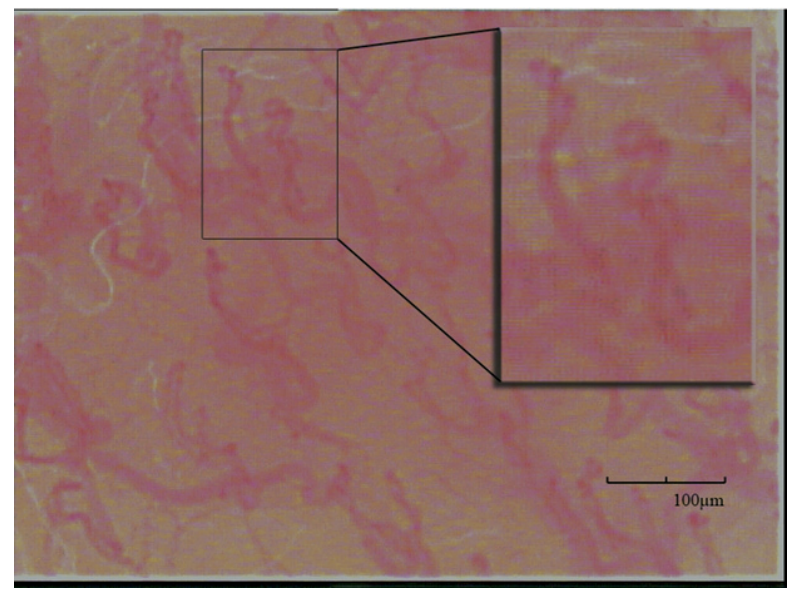

Fig. 2. Microvascular capillaroscopic characteristics of oral lichen planus showing the characteristic (tortuous, branched) loops; magnification $\times 200$.

crocirculation. This phenomenon basically includes an increase in the number of vessels in a certain area and its morphological modification, which is the expression in vivo of vessel neoformation. Angiogenesis takes place both in the presence of phlogistic processes (OLP) and in the case of tumoral transformation of a lesion, since vascular modification is however necessary for tumoral growth. It is known that OLP is an autoimmune inflammatory pathology. It is also characterized by cyclicity, with phases of remission and recrudescence. Thus, local microcirculation modifications may be linked to a greater or lesser intensity of the phlogistic phenomenon, and therefore to a greater or lesser activity of the disease. It follows that a more active pathology is linked to a greater damage to the basal epithelium, and therefore for the clinical, symp-

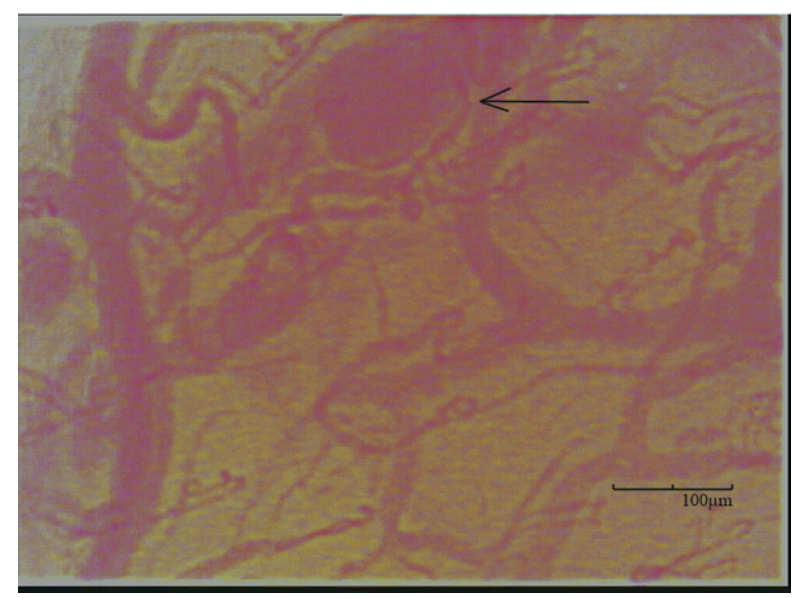

Fig. 3. Microvascular capillaroscopic characteristics of oral lichen planus showing the presence of microhemorrhages (arrow); magnification $\times 200$.

tomatological manifestation of the disease. It also follows that the greater the damage to the epithelium, the greater the difficulty of controlling it, and the risk of subsequent developments of disease "evolution." From this point of view, microcirculation observation might give us extremely useful information about the course of the disease. Our study allows for a totally nontraumatic, noninvasive in vivo observation of a parameter (local microcirculation).

Capillaroscopy has brought very important results, mainly because it has allowed us to show "in vivo" a change in local microangiotectonics in OLP patients. Some studies have evaluated microcirculation characteristics in the presence of lichen planus. ${ }^{3,4,18,19}$ Studies carried out on OLP vascular pattern have shown a statistically significant increase in vascular volume compared to normal mucosa. However, those studies did not report significant differences in vessel number between the case and the control. ${ }^{19}$

Literature data point out that, in the presence of OLP, blood vessels are dilated; therefore, they occupy a relatively wider space, but this does not correspond to an increase in vessel number. ${ }^{18,19}$ This study can add definitely new data to the studies already present in literature. First of all, the method used, i.e., capillaroscopy, is an immediate, inexpensive, and definitely nontraumatic investigation. ${ }^{11,13}$ Videocapillaroscopy has allowed us to confirm the increase in capillary diameter in OLP patients compared with the control. In fact, capillary loop diameter in OLP patients was significantly increased compared to the normal mucosa. Besides, a significant increase in capillary loop tortuosity and the presence of microhemorrhages were observed. Capillary density, together with the discovery of vas- 
Table I. Density, length, and caliber parameters of capillary loops between OLP and control groups*

\begin{tabular}{lrrr}
\hline & \multicolumn{1}{c}{ Lichen } & Control & Significance $(P$ value $)$ \\
\hline Density per $\mathrm{mm}^{2}$, mean $\pm \mathrm{SD}$ & $25.750 \pm 8.900$ & $21.170 \pm 3.900$ & $\mathrm{~S}(.036)$ \\
Loop length, mm, mean $\pm \mathrm{SD}$ & $0.200 \pm 0.056$ & $0.187 \pm 0.060$ & $\mathrm{NS}(.235)$ \\
Loop diameter, mm, mean $\pm \mathrm{SD}$ & $0.031 \pm 0.011$ & $0.026 \pm 0.009$ & $\mathrm{~S}(.002)$ \\
Efferent loop diameter, mm, mean $\pm \mathrm{SD}$ & $0.014 \pm 0.004$ & $0.008 \pm 0.002$ & $\mathrm{~S}(<.0001)$ \\
Afferent loop diameter, mm, mean $\pm \mathrm{SD}$ & $0.011 \pm 0.004$ & $0.006 \pm 0.002$ & $\mathrm{~S}(.0006)$ \\
Tortuosity mark, mean $\pm \mathrm{SD}$ & $2.210 \pm 0.400$ & $1.098 \pm 0.800$ & $\mathrm{~S}(<.0001)$ \\
\hline
\end{tabular}

$S$, significant; $N S$, not significant.

*The difference in the parameters between the OLP and the control groups was evaluated with the Mann-Whitney $U$ test with regard to nonparametric data (tortuosity), and with Student $t$ test with regard to parametric data.

Table II. Density, length, and caliber parameters of capillary loops between the three types of OLP and control groups*

\begin{tabular}{|c|c|c|c|c|}
\hline & Lichen type 3 & Lichen type 2 & Lichen type 1 & Control \\
\hline Density per $\mathrm{mm}^{2}$, mean $\pm \mathrm{SD}$ & $\begin{array}{c}24.100 \pm 5.050 \\
S\end{array}$ & $\begin{array}{c}26.050 \pm 3.880 \\
S\end{array}$ & $\begin{array}{c}20.760 \pm 6.990 \\
\text { NS }\end{array}$ & $21.170 \pm 3.900$ \\
\hline Loop length, $\mathrm{mm}$, mean $\pm \mathrm{SD}$ & $\begin{array}{c}0.200 \pm 0.070 \\
\text { NS }\end{array}$ & $\begin{array}{c}0.220 \pm 0.050 \\
\text { NS }\end{array}$ & $\begin{array}{c}0.190 \pm 0.036 \\
\text { NS }\end{array}$ & $0.187 \pm 0.060$ \\
\hline Loop diameter, mm, mean $\pm \mathrm{SD}$ & $\begin{array}{c}0.033 \pm 0.005 \\
\mathrm{~S}\end{array}$ & $\begin{array}{c}0.035 \pm 0.009 \\
\mathrm{~S}\end{array}$ & $\begin{array}{c}0.030 \pm 0.070 \\
\text { NS }\end{array}$ & $0.026 \pm 0.0091$ \\
\hline Efferent loop diameter, $\mathrm{mm}$, mean $\pm \mathrm{SD}$ & $\begin{array}{c}0.014 \pm 0.001 \\
\mathrm{~S}\end{array}$ & $\begin{array}{c}0.014 \pm 0.004 \\
\mathrm{~S}\end{array}$ & $\begin{array}{c}0.015 \pm 0.004 \\
\mathrm{~S}\end{array}$ & $0.008 \pm 0.002$ \\
\hline Afferent loop diameter, $\mathrm{mm}$, mean $\pm \mathrm{SD}$ & $\begin{array}{c}0.010 \pm 0.002 \\
\mathrm{~S}\end{array}$ & $\begin{array}{c}0.011 \pm 0.005 \\
\mathrm{~S}\end{array}$ & $\begin{array}{c}0.011 \pm 0.004 \\
\mathrm{~S}\end{array}$ & $0.006 \pm 0.002$ \\
\hline Tortuosity mark, mean $\pm \mathrm{SD}$ & $\begin{array}{c}2.150 \pm 0.140 \\
\mathrm{~S}\end{array}$ & $\begin{array}{c}2.480 \pm 0.280 \\
\mathrm{~S}\end{array}$ & $\begin{array}{c}2.110 \pm 0.490 \\
\mathrm{~S}\end{array}$ & $1.098 \pm 0.800$ \\
\hline
\end{tabular}

$S$, significant; $N S$, not significant.

*The difference in the parameters between the different clinical OLP forms and the control groups was evaluated with the Mann-Whitney $U$ test with regard to nonparametric data (tortuosity), and with Student $t$ test with regard to parametric data.

cular ramifications and tortuosity, are the parameters that permitted the evaluation in vivo of the angiogenesis process in OLP patients. ${ }^{12,16,19-24}$ Vasodilatation and revascularization are 2 processes that reflect local vascular disorder. ${ }^{16,23,24}$ This study compared parameters such as density, diameter, tortuosity, and presence of branched loops (characteristic loops) among the different clinical OLP forms (type $1=$ reticular OLP; type $2=$ atrophic OLP; type $3=$ erosive OLP). A higher density (types 2 and 3 ) and the presence of a greater number of branched, tortuous loops were observed in the atrophic form (type 2) compared to the exclusively reticular form (type 1).

Therefore, this study highlights the existence of oral microcirculation differences among healthy and OLP patients; these data can be particularly helpful in OLP program, since they might be used for a noninvasive study of the disease. Such a hypothesis is strengthened by literature data, according to which a microcirculation modification is associated with an increase in local phlogosis, and therefore in the clinical manifestation of the disease. ${ }^{3,6,7,9,10,16,23,24}$
This method might also be useful to check the effectiveness of the selected therapeutic protocol. It could permit a comparison of the characteristics of pre- and posttreatment local microcirculation, as well as an objectification or parameterization of an aspect of the program, often relying on patient information (symptoms) or on clinician evaluation. The purpose of the therapeutic protocol is to reduce the symptoms of the disease. Symptom reduction is a result of the reduction of phlogosis and of its associated angiogenetic phenomenon. Since these data can be evaluated "in vivo," our method might be very useful for checking the effectiveness of a therapy.

This study must be considered as a preliminary study, which definitely requires further investigations, mainly concerning monitoring within an adequate lapse of time; it also offers very interesting suggestions for further future studies. This method can permit a distinction between patients who do not show alterations or significant local microangiotectonics worsening, and patients who show angiogenesis phenomena worthy of further diagnostic investigations as a consequence of the biopsy collection. 
To conclude, this study can pave the way for new possibilities in the study of the microcirculation of patients suffering from OLP, with particular reference to the angiogenic phenomenon.

\section{REFERENCES}

1. Montebugnoli L, Foschini M, Marchetti C, Farnedi A, Pession A. [Gestione del paziente affetto da manifestazioni lichenoidi.] Dental Cadmos 2005;2:3-25. Italian.

2. Scardina GA, Carini F, Maresi E, Messina P. A randomized trial assessing the effectiveness of different concentrationes of isotetinoen in the managment of oral lichen planus. Int J Oral Maxillofac Surg 2005;35:56-60.

3. Banberger ES, Perrett CW. Angiogenesis in benign, pre-malignant and malignant vulvar lesions. Anticancer Res 2002;22(6C):3853-65.

4. Ben-Av P, Crofford LJ, Wilder RL, Hla T. Induction of vascular endothelial growth factor expression in synovial fibroblast by prostaglandin $\mathrm{E}$ and interleukin-1: a potential mechanism for inflammatory angiogenesis. FEBS Lett 1995;372:83-7.

5. Ferrara N. The role of vascular endothelial growth factor in pathological angiogenesis. Breast Cancer Res Treat 1995;36:127-37.

6. Folkman J. Angiogenesis in cancer, vascular, rheumatoid and other disease. Nature Med 1995;1:27-31.

7. Hanahan D, Folkman J. Patterns and emerging mecanisms of the angiogenic switch during tumorigenesis. Cell 1996;86:353-64.

8. Li J, Perrella MA, Tsai JC, Yet SF, Hsieh CM, Yoshizumi $\mathrm{M}$, et al. Induction of vascular endothelial growth gene expression factor by interleukin-1-b in rat aotic smooth muscle cells. J Biol Chem 1995;270:308-12.

9. O'Reilly MS, Boehm T, Shing Y, Folkman J. Endostatin: an endogenous inhibitor of angiogenesis and tumor growth. Cell 1997;88:277-85.

10. Silverman S Jr. Oral lichen planus: a potentially premalignant lesion. J Oral Maxillofac Surg 2000;58:1286-8.

11. Cantatore FP, Corrado A, Covelli M, Lapadula G. Morphologic study of the microcirculation on connettive tissue disease. Ann Ital Med Int 2000;15:273-81.

12. Hern S, Mortimer PS. Visualization of dermal blood vesselscapillaroscopy. Clin Exp Dermatol 1999;24:473-8.

13. Scardina GA, Messina P, Carini F. Vasodilatation of human gingiva and neurogenic inflammation. Clin Hemorheol Microcirc 2005;32:279-85.

14. Wright J. Oral lichen planus. Br Dent J 2004;197:224-5.

15. Folkman J. Angiogenesis and angiogenesis inhibition: an overview, regulation of angiogenesis. EXS 1997;79:1-8.

16. Newell B, Bedlow AJ, Cliff S, Drysdale SB, Stanton AW, Mortimer PS. Comparison of the microvasculature of basal cell carcinoma and actinic keratosis using intravital microscopy and immunohistochemistry. Br J Dermatol 2003;149:105-10.

17. Tipoe GL, Jin Y, White FH. The relationship between vascularity and cell proliferation in human normal and pathological lesions of the oral cheek epithelium. Eur J Canc 1996;32B(1):24-31.

18. Forsythe JA, Jiang BH, Iyer NV, Agani F, Leung SW, Koos RD, et al. Activation of vascular growth factor gene transcription by hypoxia-inducible factor 1. Mol Cell Biol 1996;16:4604-13.

19. Lopez de Blanc S, Gendelman H, Itoiz ME, Lanfranchi H. Study of vascular pattern in oral lichen planus. Acta Odontol Latinoam 1996;9:27-36.

20. Bussolino F, Mantovani A, Persico G. Molecular mechanisms of blood vessels formation. TIBS 1998;22:251-6.

21. Ferrara N, Davis Smyth T. The biology of vascular endothial growth factor. Endocr Rev 1997;18:4-25.

22. Jin Y, Tipoe GL, White FH, Yang L. A quantitative investigation of immunocytochemically stained blood vessels in normal, benign, premalignant and malignant human oral cheek epithelium. Virchows Arch 1995;427:145-51.

23. Newell B, Bedlow AJ, Cliff S, Drysdale SB, Stanton AW, Mortimer PS. Comparison of the microvasculature of basal cell carcinoma and actinic keratosis using intravital microscopy and immunohistochemistry. Br J Dermatol 2003;149:105-10.

24. Roberts CC, Stanton AW, Pullen J, Bull RH, Levick JR, Mortimer PS. Skin microvascular architecture and perfusion studied in human postmastectomy oedema by intravital video-capillaroscopy. Int J Microcirc Clin Exp 1994;14:327-34.

Reprint requests:

Giuseppe Alessandro Scardina, DDS, PhD

University of Palermo

Oral Science

Via Del Vespro, 129

20127 Palermo, Italy

scardina@odonto.unipa.it 